\title{
Investigation of Neonatal Staff Members' Attitudes toward End-of-Life Decision Making about Dying New- borns
}

Jin-Hyeok Lee, M.D., Sun-Young Cho, M.D., Kyoung-Ah Kwon, M.D., and Myo-Jing Kim, M.D.

Department of Pediatrics, Dong-A University College of Medicine, Busan, Korea

\section{ABSTRACT}

Purpose: The objective of this study was to investigate physicians' attitudes toward ethical end-of-life decision making about dying newborns.

Methods: Between October and December 2015, we surveyed 185 neonatal staff members working at 6 neonatal intensive care units to investigate their attitudes toward ethical end-of-life decision making about dying newborns.

Results: The respondents generally agreed with using sedatives/analgesics to suppress pain despite the risk of fatality $(80 \%)$, continuing current treatment without using other treatment methods (56.2\%), and withholding emergency treatment in the form of cardiac arrest resuscitation (48.1\%). In contrast, most respondents disagreed with administering drugs for the purpose of ending life, withholding neonatal intensive care, and withholding mechanical ventilation. Although the respondents believed that it is necessary to suggest that the parents of dying neonates sign do-notresuscitate (DNR) orders (62.7\%), most of them found it difficult to talk to parents/ families about DNR orders (90.8\%), or wanted to refrain from obtaining families' consent in person (84.9\%).

Conclusion: Korean neonatal staff members believed that withholding or withdrawal of treatment is necessary when making ethical decisions about dying neonates; however, they preferred to use conservative, rather than active interventions.

Key Words: End-of-life care, Ethics, Neonatal intensive care units, Newborns

\section{INTRODUCTION}

Over the last five decades, Korea's neonatal intensive care has improved greatly ${ }^{11}$. However, aside from improved survival rates, the long-term outcomes remain unsatisfactory $^{2,3)}$. Thus, arguments surrounding the maintenance of invasive treatments for neonates without any hope of recovery have increased in the medical field ${ }^{4}$. Moreover, neonatal staff members now face a new dilemma: end-of-life decision making about dying
Received: 25 November 2016

Revised: 15 February 2017

Accepted: 16 March 2017

Correspondence to: Myo-Jing Kim

Department of Pediatrics, Dong-A

University College of Medicine, 1,3-ga, Dongdaesin-dong, Seo-gu,

Busan 602715, Korea

Tel: +82-51-240-2589

Fax: +82-51-242-2765

E-mail: myojing@dau.ac.kr

Copyright(c)

By Korean Society of Neonatology.

All right reserved.

This is an Open-Access article distributed under the terms of the Creative Commons Attribution Non-Commercial License (http://creativecommons.org/licenses/ by-nc/4.0), which permits unrestricted non-commercial use, distribution, and reproduction in any medium, provided the original work is properly cited. 
newborns ${ }^{5-7)}$.

In a study that investigated the ethical decision-making attitudes of neonatal intensive care units (NICUs) staff in 10 European countries, most people agreed with the continuation of treatment without intensification, withholding of emergency maneuvers, and withholding of intensive care, in limited contexts ${ }^{8)}$. However, such survey results can differ according to the cultural background of each country, rather than individual staff members' tendencies.

In Korean NICUs, do-not-resuscitate (DNR) orders, which involve withholding cardiac resuscitation when it is required in cases without hope of recovery, are considered a method of end-of-life care for dying neonates; however, no study has investigated the ethical perspectives in relation to this aspect in detail. Therefore, the present study aimed to investigate Korean neonatal staff members' attitudes toward ethical end-of-life decision making about dying newborns.

\section{MATERIALS AND METHODS}

\section{Respondents}

Participants were neonatal staff members working at level III neonatal intensive care units with clinical ethics committees in Korea (five neonatal intensive regional centers and one local neonatal intensive care unit). We focused on NICUs in training hospitals where preterm infants weighing less than 1,500 g can be treated and where neonatal subspecialists are available. Participants comprised neonatal subspecialists, fellows, residents, and nurses who worked in the NICUs.

\section{Survey}

Questionnaires were distributed and collected in person with the assistance of managers at the NICUs to each unit from October to November 2015, and the data that were collected by December 2015 were analyzed. The questionnaire comprised three parts: general sociodemographic characteristics, personal views regarding end-of-life decision making for neonates, and attitudes toward DNR orders. In terms of sociodemographic characteristics, we assessed the respondents' gender, age, whether they were doctors or nurses, their length of experience in NICUs, and religious background. On the basis of the surveys conducted in Europe ${ }^{4,8,9)}$, we assessed the respondents' personal views (agreement and disagreement) regarding seven categories of end-of-life decision making about neonates. Six categories were used to assess the respondents' opinions and attitudes toward DNR orders for dying newborns ${ }^{9,10)}$. Respondents were asked to indicate whether they strongly agreed, somewhat agreed, were unsure, somewhat disagreed, or strongly disagreed with each category. "Strongly agree" and "somewhat agree" responses were analyzed as agreement, and "somewhat disagree" and "strongly disagree" responses were analyzed as disagreement. All the questions in the surveys we used as reference materials were written in English; therefore, one neonatal subspecialist, one medical ethicist, and one nurse who is also a licensed English teacher translated the questions into Korean, and the final survey was formulated upon agreement among these experts.

\section{Statistical analysis}

Statistical analyses were performed on a personal computer using SPSS version 18.0 (SPSS Inc., Chicago, IL, USA). Fisher's exact tests were used for the comparisons of categorical data, for example, gender and religious beliefs. Independent $t$ tests or oneway analyses of variance were used for two-group (or more than two-group) comparisons. The corresponding nonparametric methods, i.e., Mann-Whitney $U$ or Kruskal-Wallis tests, were used whenever the data normality assumption was not satisfied. Statistical significance was set at $P<0.05$.

\section{Ethics statement}

The study protocol was approved by the institutional review board of Dong-A Medical Center. Informed consent was obtained from all the participants, as confirmed by the board.

\section{RESULTS}

\section{Sociodemographic characteristics}

We distributed 193 questionnaires and collected 185 (response rate $=95.9 \%$ ). Among these, 40 were from neonatal doctors and 145 from neonatal nurses. The participants' demographic details are displayed in Table 1.

\section{Personal views regarding end-of-life decision making about dying neonates}

Half of the respondents generally agreed with the following three major end-of-life care methods: using sedatives/analgesics to suppress pain despite the risk of fatality $(80 \%)$, continuing 
current treatment without using other treatment methods (56.2 $\%$ ), and withholding emergency treatment in the form of cardiac arrest resuscitation (48.1\%). In contrast, most respondents disagreed with administering drugs for the purpose of ending life, withholding neonatal intensive care, and withholding mechanical ventilation (Table 2).

There was no difference in the level of agreement of the respondents with respect to neonatal intensive care unit working experience, sociodemographic characteristics, or religious beliefs. By job category, doctors agreed more with continuing the

Table 1. Sociodemographic Characteristics of Respondents

\begin{tabular}{lccc}
\hline & \multicolumn{3}{c}{ Number (\%) } \\
\cline { 2 - 4 } Characteristics & Total & $\begin{array}{c}\text { Neonatal } \\
\text { doctors }\end{array}$ & $\begin{array}{c}\text { Neonatal } \\
\text { nurses }\end{array}$ \\
\hline Age (y) & $43(23.2)$ & $0(0.0)$ & $43(29.7)$ \\
$20-25$ & $70(37.8)$ & $14(35.0)$ & $56(38.6)$ \\
$26-30$ & $56(30.3)$ & $23(57.5)$ & $33(22.8)$ \\
$31-40$ & $16(8.6)$ & $3(7.5)$ & $13(9.0)$ \\
Over 40 & & & \\
Gender & $173(93.5)$ & $29(72.5)$ & $144(99.3)$ \\
Female & $12(6.5)$ & $11(27.5)$ & $1(0.7)$ \\
Male & & & \\
Religious background & $34(18.4)$ & $3(7.5)$ & $31(21.4)$ \\
Christian & $56(30.3)$ & $20(50.0)$ & $36(24.8)$ \\
Catholic & $94(50.8)$ & $17(42.5)$ & $77(53.1)$ \\
Buddhist & $1(0.5)$ & $0(0.0)$ & $1(0.7)$ \\
None & & & \\
Experience in NICU (y) & $134(72.4)$ & $32(80.0)$ & $102(70.4)$ \\
$1-5$ & $31(16.8)$ & $5(12.5)$ & $26(17.9)$ \\
6-10 & $20(10.8)$ & $3(7.5)$ & $17(11.7)$ \\
Over 10 & & & \\
\hline
\end{tabular}

Abbreviation: NICU, neonatal intensive care unit. current treatment without using other treatment methods $(70.7 \%$ vs. $51 \%, P=0.03$ ) and withholding emergency treatment in the form of cardiac arrest resuscitation $(75 \%$ vs. $39.6 \%, P<0.01)$ than nurses.

There were no consistent tendencies according to age, although there were differences in the level of agreement for with holding intensive care, i.e., resuscitation at birth or mechanical ventilation (20-25 years: $18.2 \%, 26-30$ years: $32.4 \%$, 31-40 years: $15.8 \%$, over 40 years: $41.2 \%, P=0.04$ ).

Males agreed more with withholding emergency treatment in the form of cardiac arrest resuscitation than females (84.6\% vs. $44.6 \%, P<0.01)$.

\section{Attitudes toward DNR orders}

Most respondents believed that it was necessary to suggest to the parents of dying neonates that they sign the DNR orders (62.7\%). However, most respondents found it difficult or did not find it rewarding to talk to parents/families about DNR orders (90.8\%) or to obtain consent for such orders (84.9\%). Over half of the respondents agreed that recommendations to parents of dying neonates that they sign DNR orders should first be approved by clinical ethics committees (Table 3).

There was no difference in the level of agreement by sociodemographic characteristics, such as sex or religious beliefs. By job category, nurses agreed more with recommending that parents of dying neonates sign a DNR order that was approved beforehand by a clinical ethics committee (74.5\% vs. $51.7 \%, P=$ 0.02). Respondents who were 40 years of age or younger agreed more with suggesting that parents of dying neonates sign a DNR order (20-25 years: $83.9 \%$, 26-30 years: $85.7 \%$, 31-40 years: 87.5\%, over 40 years: $56.2 \%, P=0.03$ ), and respondents with less work experience agreed more that talking to parents/families

Table 2. Participants' Agreement with End-of-Life Decision Making about Dying Neonates by Country

\begin{tabular}{|c|c|c|c|c|c|c|c|c|c|}
\hline Category & IT (\%) & ES (\%) & FR (\%) & DE (\%) & NL (\%) & UK (\%) & SE (\%) & TW (\%) & $\mathrm{KR}^{*}(\%)$ \\
\hline Continue current treatment without using other treatment methods & 81 & 85 & 83 & 95 & 89 & 86 & 95 & 70.2 & 56.2 \\
\hline $\begin{array}{l}\text { Withholding intensive care, i.e., resuscitation at birth or mechanical } \\
\text { ventilation }\end{array}$ & 157 & 74 & 67 & 81 & 95 & 91 & 82 & 43.3 & 24.9 \\
\hline Withholding emergency treatment, i.e., cardiac arrest resuscitation & 53 & 63 & 82 & 82 & 95 & 92 & 88 & 75 & 48.1 \\
\hline Withdrawing life-saving drugs & 44 & 66 & 66 & 95 & 96 & 91 & 68 & 32.7 & 38.4 \\
\hline Withdrawing mechanical ventilation & 29 & 50 & 59 & 74 & 99 & 97 & 94 & 10.6 & 29.2 \\
\hline Using sedatives/analgesics to suppress pain despite the risk of fatality & 64 & 87 & 96 & 86 & 98 & 93 & 95 & 34.6 & 80 \\
\hline Administering drugs for the purpose of ending life & 5 & 6 & 73 & 8 & 71 & 15 & 3 & 2.9 & 8.2 \\
\hline
\end{tabular}

*Results of this present study.

Abbreviations: DE, Denmark; ES, Spain; FR, France; IT , Italy; KR , South Korea; NL , Netherlands; SE, Sweden; TW, Taiwan; UK, United Kingdom. 
Table 3. Participants' Attitudes toward DNR Orders

Categories

Agreement, \%

Talking to parents/families about DNR orders is difficult

90.8

The DNR informed consent form in your hospital is dear to you

57.8

Obtaining consent for DNR orders is more of a chore than a rewarding task

84.9

I agree with suggesting that parents of dying neonates sign a DNR order

62.7

I am confident about discussing consent for medical procedures

58.9

Recommending that parents of dying neonates sign a DNR order should be approved beforehand by a clinical ethics committee

50.8

Abbreviation: DNR, do not resuscitation.

about DNR orders is difficult (1-5 years: $95.5 \%, 6-10$ years: 93.5\%, over 10 years: $80.6 \%, P=0.04)$.

\section{DISCUSSION}

Our participants generally agreed with using sedatives/ analgesics to suppress pain despite the risk of fatality, continuing current treatment without using other treatment methods, and withholding emergency treatment in the form of cardiac arrest resuscitation. However, they disagreed with administering drugs for the purpose of ending life, withholding neonatal intensive care (i.e., resuscitation at birth or mechanical ventilation), and withdrawing mechanical ventilation. In other words, the respondents agreed more with using conservative, rather than active, interventions in relation to end-of-life decision making about dying neonates; these results are similar to the findings obtained from studies conducted in other Asian countries ${ }^{9,11)}$. In contrast, our results differ from those obtained from studies conducted in European countries, where many doctors agreed with using active interventions, such as withdrawal of mechanical ventilation $^{8,12-15)}$. Interestingly, the respondents agreed most with active interventions required for reducing pain (80\%); this differs from findings of other studies conducted in Asian countries but is similar to the high agreement rate observed in European studies $^{4,8,15)}$.

Although the respondents replied that it was necessary to suggest to parents of dying neonates that they sign DNR orders (62.7\%), the agreement rate was much lower than that observed in another study $(86.5 \%)^{9)}$. Moreover, in this study, we also observed a clearer tendency toward the respondents finding it difficult or wanting to refrain from suggesting DNR orders or obtaining consent from families in person ${ }^{9)}$. Over half (50.8\%) of our respondents agreed that DNR order recommendations should first be approved by clinical ethics committees, which is lower than the rates observed in other studies (61.5\% and 94.2\%) $)^{9,11)}$

According to our findings, Korean neonatal staff members believe that withholding or withdrawal of treatment is necessary while making ethical decisions about dying neonates. However, they preferred using conservative, rather than active, interventions and also valued reducing pain. Furthermore, they perceived that it was difficult and tiring to explain the DNR orders to parents, and to obtain consent from parents and ethics committees. In the US, the ethical considerations for neonatal care have been discussed since the 1980s, and ethical laws for neonatal care, most notably the Baby Doe Law and Baby Jane Doe Law, have been established ${ }^{16,17)}$. If a child has "lethal" anomalies or a "terminal" condition, the courts generally find that parents are the primary decision makers concerning the level of care $^{18)}$. In Korea, the guidelines for withdrawing lifesustaining treatment were announced in 2009. These are based on the self-determination rights of the patient and the medical judgment on the status of the patient; therefore, there are limitations in applying them to neonatal care ethics ${ }^{19)}$.

"The Act on Decisions on the Use of Hospice Palliative Care and Life-Sustaining Treatment on Patients Nearing the End of Life," which will take effect in $2017^{20)}$, mainly concerns the dying process and life-sustaining treatment for terminally ill cancer patients. For neonates, the decision must be made by their legal guardian; the authority and role of the guardian are similar to those of a person with medical power of attorney. In addition, an ethical dilemma may arise in which the decision made by the guardian may not be in the best interest of the neonate, or there may be disagreements in determining what would ensure the best interests of the neonate. Considering these scenarios, no clear agreement has been reached on end-of-life decisions about terminal stage patients without any hope of recovery, and laws on this matter are also lacking in Korea; therefore, many staff members experience difficulties with ethical decision making in 
this regard.

Newborn patients cannot make their own decisions, and the rights of newborns and parents might conflict with the welfare system $^{21)}$. When it is clear that life-sustaining treatment does not lead to the well-being of the newborn, family, and society, neonatal staff members must often make judgments about withdrawing treatment from a medical perspective. In this regard, European countries actively seek to directly or indirectly reflect the opinions of parents in ethical decision making, even in cases where their opinions conflict with those of neonatal staff members ${ }^{22-25)}$.

Therefore, it is also necessary to establish a clear, mutually agreed-upon policy regarding ethical medical judgments in Korea. Moreover, neonatal staffs must be educated on end-of-life decision making.

This study was a survey, which was carried out in six neonatal intensive care units. It has limitations, such as the data can be generalized only in the context of neonatal medical ethics in Korea. Additionally, this study did not reflect the variety of clinical situations in which ethical decisions must be made. There was also the limitation that information was not obtained regarding whether official procedures were in place through the Hospital Ethics Committee or the Brain Death Decision Committee. However, this study is valuable in that it reports the ethical perceptions of medical staff regarding dying newborns without a chance of recovery. In future, research on neonatal medical ethics in Korea should target additional neonatal intensive care units; this study provides a basis for such further studies.

\section{ACKNOWLEDGMENTS}

We express our sincere gratitude to Dr. Do Kyung Kim for her advice regarding this study. This study was supported by the Dong-A University Research Fund.

\section{DISCLOSURE}

The authors have no conflicts of interest to declare.

\section{REFERENCES}

1) Shim JW, Jin HS, Bae CW. Changes in survival rate for verylow-birth-weight infants in Korea: comparison with other countries. J Korean Med Sci 2015;30:S25-34.

2) Ahn SY, Shim SY, Sung IK. Intraventricular hemorrhage and post hemorrhagic hydrocephalus among very-low-birthweight infants in Korea. J Korean Med Sci 2015;30:S52-8.

3) Jo HS, Cho KH, Cho SI, Song ES, Kim BI. Recent changes in the incidence of bronchopulmonary dysplasia among very-lowbirth-weight infants in Korea. J Korean Med Sci 2015;30:S81-7.

4) Cuttini M, Nadai M, Kaminski M, Hansen G, de Leeuw R, Lenoir S, et al. End-of-life decisions in neonatal intensive care: physicians' self-reported practices in seven European countries. Lancet 2000;355:2112-8.

5) American Academy of Pediatrics. Committee on Bioethics and Committee on Hospital Care. Palliative care for children. Pediatrics 2000;106:351-7.

6) El Sayed MF, Chan M, McAllister M, Hellmann J. End-of-life care in Toronto neonatal intensive care units: challenges for physician trainees. Arch Dis Child Fetal Neonatal Ed 2013;98: F528-33.

7) Larcher V. Ethical considerations in neonatal end-of-life care. Semin Fetal Neonatal Med 2013;18:105-10.

8) Cuttini M, Casotto V, de Vonderweid U, Garel M, Kollee LA, Saracci R. Neonatal end-of-life decisions and bioethical perspectives. Early Hum Dev 2009;85:S21-5.

9) Huang LC, Chen CH, Liu HL, Lee HY, Peng NH, Wang TM, et al. The attitudes of neonatal professionals towards end-of-life decision-making for dying infants in Taiwan. J Med Ethics 2013;39:382-6.

10) Sulmasy DP, He MK, McAuley R, Ury WA. Beliefs and attitudes of nurses and physicians about do not resuscitate orders and who should speak to patients and families about them. Crit Care Med 2008;36:1817-22.

11) Bilgen H, Topuzoğlu A, Kuşçu K, Altuncu E, Özek E. End-of-life decisions in the newborn period: attitudes and practices of doctors and nurses. Turk J Pediatr 2009;51:248-56.

12) Rebagliato M, Cuttini M, Broggin L, Berbik I, de Vonderweid U, Hansen G, et al. Neonatal end-of-life decision making: physicians' attitudes and relationship with self-reported practices in 10 European countries. JAMA 2000;284:2451-9.

13) Cuttini M, Casotto V, Orzalesi M. Ethical issues in neonatal intensive care and physicians' practices: a European perspective. Acta Paediatr Suppl 2006;95:42-6.

14) Orzalesi MM, Cuttini M. Ethical issues in neonatal intensive care. Ann Ist Super Sanità 2011;47:273-7.

15) Willems DL, Verhagen AAE, van Wijlick E. Infants' best 
interests in end-of-life care for newborns. Pediatrics 2014; 134:e1163-8.

16) Weiner J, Sharma J, Lantos J, Kilbride H. How infants die in the neonatal intensive care unit: trends from 1999 through 2008. Arch Pediatr Adolesc Med 2011;165:630-4.

17) Fanaroff JM, Hascoet JM, Hansen TW, Levene M, Norman M, Papageorgiou A, et al. The ethics and practice of neonatal resuscitation at the limits of viability: an international perspective. Acta Paediatr 2014;103:701-8.

18) Fanaroff JM, Turbow R. Legal issues in neonatal-perinatal medicine. In: Martin RJ, Fanaroff AA, Walsh MC, editors Fanaroff and Martin's neonatal-perinatal medicine: disease of the fetus and infant. 10th ed. Elsevier, 2015:41-58.

19) Kim YC. The Legal nature and penal implications of the supreme court's decision on termination of life-sustaining treatment-regarding the supreme court judgment 2009-Da-17417 sentenced May 21, 2009. Ilganlaws 2011;20:587-633.

20) The use of hospice palliative care and life-sustaining treatment on patients nearing the end of life Act of 2017, Pub. L. No.14013
(August 4, 2017).

21) Guimarães H, Rocha G, Bellieni C, Buonocore G. Rights of the newborn and end-of-life decisions. J Matern Fetal Neonatal Med 2012;25:76-8.

22) Weiner J, Sharma J, Lantos J, Kilbride H. Does diagnosis influence end-of-life decisions in the neonatal intensive care unit? J Perinatol 2015;35:151-4.

23) Murakami M, Yokoo K, Ozawa M, Fujimoto S, Funaba Y, Hattori M. Development of a neonatal end-of-life care education program for NICU nurses in Japan. J Obstet Gynecol Neonatal Nurs 2015;44:481-91.

24) Janvier A, Barrington K, Farlow B. Communication with parents concerning withholding or withdrawing of life-sustaining interventions in neonatology. Semin Perinatol 2014;38:38-46.

25) Dorscheidt JH, Verghagen E, Sauder PJ, Hubben JH. Medication regimes in the context of end-of-life decisions in neonatology: legal considerations with regard to Dutch NICU-practice. Med Law 2012;31:671-85. 